\title{
Konsep Hak Ekonomi dan Hak Moral Pencipta Menurut Sistem Civil Law dan Common Law
}

\author{
Hendra Tanu Atmadja
}

\begin{abstract}
Copyright is the legal protection extended to the owner of rights in an original work that he has created. If comprises two main sets of rights: the economic rights and the moral rights. The economic rights are the rights to obtain the economic. benefits derived from the copyright work as well as from the related right work. Conversely, the moral rights include the author's right to object any distortion, mutilation or other modification of his work that right be prejudicial to his honor or reputation. The concept of copyright was originally from the legal system of the continent, the civil law countries such as French and German focus exclusively on individual copyright work, whereas the common law countries like the United States of America and England focus on the ownership of copyright works.
\end{abstract}

\section{Pendahuluan}

Dewasa ini Indonesia telah memiliki Undang-undang Nomor 6 Tahun 1982 tentang Hak Cipta yang telah diubah dengan Undangundang Nomor 7 Tahun 1987, yang telah diubah dengan Undang-undang Nomor 12 Tahun 1997, tentang Hak Cipta. Walaupun perubahan itu telah berusaha mengakomodasi ketentuan-ketentuan dalam TRIPS (The. Agreement on Trade Related Aspects of Intellectual Property Rights), namun masih perlu disempurnakan untuk memberi perlindungan bagi karya-karya tersebut di bidang Hak Cipta, khususnya Hak Terkait, termasuk pula upaya untuk memajukan perkembangan karya intelektual yang.berasal dari keanekaragaman seni dan budaya tersebut di atas. Dari bebe- rapa konvensi di bidang Hak Kekayaan Intelektual ada, dan berdasarkan beberapa ketentuan, sudah sepatutnya diberi perlindungan yang lebih jelas terhadap karya cipta musik luar negeri tersebut.

Dengan memperhatikan hal-hal di atas, dipandang perlu untuk mengganti Undangundang Hak Cipta dengan yang baru. Hal ini disadari karena kekayaan seni dan budaya, serta pengembangan kemampuan intelektual masyarakat Indonesia memerlukan perlindungan hukum yang memadai agar terdapat iklim persaingan usaha yang sehat yang diperlukan dalam melaksanakan pembangunan nasional. 


\section{Hak Ekonomi dan Hak Moral Pencipta}

Hak Cipta terdiri atas hak ekonomi (economic rights) dan hak moral (moral rights). Hak ekonomi adalah hak untuk mendapatkan manfaat ekonomi atas Ciptaan serta produk Hak Terkait. Hak moral adalah hak yang melekat pada diri Pencipta atau Pelaku yang tidak dapat dihilangkan atau dihapus tanpa alasan apapun, walaupun Hak Cipta atau Hak Terkait telah dialihkan.

Hak cipta terdiri dari hak ekonomi (economic rights) dan hak moral (moral rights). Hak ekonomi adalah hak untuk mendapatkan manfaat ekonomi atas suatu karya cipta serta produk Hak Terkait (neighring rights). Sedangkan hak moral adalah hak yang melekat pada diri Pencipta atau Pelaku yang tidak dapat dihapus atau dihilangkan (inalienable) dengan alasan apapun, meskipun Hak Cipta tau Hak Terkair tersebut elah dialihkan kepada pihak lain. Konsep Hak Moral berasal dari sistem hukum Eropa Kontinental, negara-negarayang menganut sistem Civil Law, seperti Perancis dan Jerman memfokuskan secara eksklusif terhadap ciptaan individual, sedangkan negara-negara Common Law, seperti Amerika Serikat dan Inggris memfokus kepada kepemilikan hak cipta. Konsep Hak Moral Eropa Kontinental tidak ditemukan dalam Undang-Undang Hak Cipta Amerika Serikat dan Inggris.
Di dalam hak cipta di samping adanya konsep häk cipta sebagai hak ekonomi, ada pula konsep hak cipta sebagai hak moral.

\section{Hak Ekonomi Pencipta}

Hak ekonomi di dalam hak cipta juga disebut hak eksploitasi, hal ini antara lain meliputi:

1. Hak untuk memperbanyak ciptaan.

2. Hak untuk mengumumkan ciptaan.

3. Hak untuk mentransformasikan ciptaan atau mengalihkan ciptaan

4. Hak untuk mereproduksi ciptaan. ${ }^{1}$

Hak-hak ekonomi seringkall disinonimkan dengan hak-hak eksploitasi, hal ini disebabkan oleh karena hak cipta memberikan jangka waktu tertentu untuk mengeksploitasi manfaat ekonomi karya cipta kepada pencipta. Kegiatan eksploitasi dapat berupa kegiatan pelaku (performer) di mana seorang penyanyi melantunkan sebuah lagu (ciptaan) musik yang direkam dalam compact disc atau kaset oleh produser rekaman untuk dijual secara umum kepada para konsumen. ${ }^{2}$

Hak ekonomi adalah hak-hak yang meliputi hak reproduksi, adaptasi, distribusi dan komunikasi (penyiaran, pengabelan (cabling) dan pertunjukan publik). ${ }^{3}$

Pencipta musik atau lagu mempunyai hak ekonomi yang merupakan hak eksklusif. Hak ekonomi yang sifatnya mendatangkan manfaat

'Menurut Undang-Undang No. 12 Tahun 1997 tentang Hak Cipta, Pasai2 dan 3, hak-hak eksploitasi dari hak cipta adalah sesuai dengan asas nemoplus, ialah hak yang dapat beralih atau dalihkan secara keseluruhan atau sebagian karena alasan waris, hibah, wasiat, jad milik negara dan perjanjian.

${ }^{2}$ Eddy Damian, Hukum Hak Cipta menurut Beberapa Konvensi Intemasional, Undang-undang Hak Cipta 1997 dan Pertindungannya terhadap Buku serta Pejanjian Penerbitannya (Bandung: PT. Alumni, 1999), him. $62-63$.

$$
{ }^{3} \mathrm{lbid}, \mathrm{hlm} .268 .
$$


ekonomi kepada pencipta dapat menimbulkan sengketa. Hak ekonomi ini dapat berupa hak mengumumkan (performing rights) dan hak menggandakan (mechanical rights). Performing Rights ${ }^{4}$ atau juga disebut performance right adalah satu dari sekumpulan hak yang diperoleh dari kepemilikan hak cipta, yang memberikan kuasa kepada pemegang hak cipta untuk mengontrol pertunjukan publik dari sebuah lagu. Setiap pertunjukan publik mengharuskan user untuk membayar fee atau royalti kepada pemegang hak cipta dan penulis lagu. Performingrights, pada umumnya disiarkan oleh stasiun televisi, pesawat radio, pub, karaoke atau melalui pementasan, konser, pagelaran dan lain-lainnya. Sedangkan yang dimaksud dengan Mechanical Rights, ${ }^{5}$ adalah satu dari sekumpulan hak yang diperoleh dari kepemilikan hak cipta yang memberikan kuasa kepada pemegang hak cipta untuk mengontrol reproduksi secara mekanis sebuah lagu, tanpa mengurangi ketentuan lisensi

"Thim Whitsett, op.cit., hal. 176.

${ }^{5}$ Ibid., hlm. 142.

${ }^{6}$ Royalti pada umumnya dipahami sebagai bentuk khusus fee dari pencipta yang mendapatkan bagian (share) dalam. keuntungannya yang diperoleh dari penggunaan karyanya. Royalti biasanya dalam bentuk pendistribusian karya karyayang direproduksi atau pengulangan pertunjukan (repeated performance). Royalti pada umumnya ditetapkan secara persentase yang dihitung dari harga ecerproduk tersebut atau yang dhitung menurut perolehan hasil loket penjualan karcis bruto bioskop yang dibayar kepada pencipta secara berkala menurut jumlah karya cipta yang terjual atau yang diperoleh dari pertunjukan, dikutip dari, WIPO Glossary of Terms of The Law of Copyright and Neighboring Rights, (World Intellectual Property Organization, Geneva, 1980), him. 231. Bdgk., Sarah Jones, op.cit., hal. 210, yang mendefinisikan royalti sebagai imbalan atau bayaran dari hak mempergunakan materi yang dilindungi hak ciptanya, atau kompensasi untuk jasa-jasanya (seperti jasa-jasa melalui artis rekaman atau produser rekaman). Dalam sebuah kontrak atau lisensi royalti biasanya đisebutkan dalam dollardan sen untuk unityang dipakai pada setiap karya yang dibuat, didistribusikan atau djualberdasarkan persentase yang diterima. Jadi seorang penulis lagu dapat menerima sebagai kompensasi atas hak cipta komposisinya, royalti diberikan 50 prosen dari hasil net yang dipungut oleh publisher musik. Seorang artis rekaman mendapatkan royalti 10 prosen sebagai kompensasi dari pementasannya sebagai artis, yang diperoleh dari hasil net yang diwujudkan dari penjualan rekamannya yang dikurangi pungutan seperti container charge dan sebagainya. wajib dari Undang-Undang Hak Cipta. Mechanical rights, perekaman karya musik atau lagu dalam bentuk kaset, piringan hilam, VCD (video compact disc), $\mathrm{CD}$ (compact disc), film dan video clips.

Salah satu usaha untuk mengeksploitasi hak-hak ekonomi suatu lagu atau musik, pencipta dapat:

sendiri atas karya ciptanya itu guna diambil manfaat ekonominya, atau

b. mengalihkan hak ciptanya itu kepada pihak lain melalui suatu perjanjian, dan atau

beritikad baik atas pengeksploitasian karya ciptanya itu.

Dalam hal hak cipta digandakan, disebarluaskan oleh pihak lain, yakni oleh user, atau pemakai, maka user harus meminta izin dari pencipta atau pemegang hak cipta. Pada umumnya permintaan izin dari pencipta atau dari pemegang hak cipta diwakill oleh sebuah badan pemungut royalti, seperti YKCl (Yayasan 
Karya Cipta Indonesia) di Indonesia, BMI (Broadcast Music, Inc.), ASCAP (American Society of Composers, Authors and Publishers) di Amerika Serikat, PRS (Performing Right Society Limited) di negara Inggris, BUMA (The performing right society in the Netherland) di negara Belanda, atau JASRAC (Japanese Society for Rights of Authors, Composers, and Publishers) di Jepang. User ini juga wajib membayar royalti kepada organisasi pemungut royalti tersebut. Untuk Indonesia, baru pencipta atau pemegang hak cipta yang memiliki wadah pemungutan royalti, sebaliknya, untuk karya cipta yang lain belum ada wadah yang mewakilinya, seperti seni sastera, seni tari dan seni drama.

Fungsi dan sifat hak cipta dapat dilihat di dalam Pasal 2 ayat (1) Undang-Undang Hak Cipta nasional, antara lain, menyebutkan bahwa yang dim̄aksud dengan "hak eksklusif" adalah hak untuk mengumumkan atau memperbanyak ciptaanya, yang timbul secara otomatis setelah suatu ciptaan dilahirkan tanpa emngurangi pembatasan memuat peraturan perundangundangan yang berlaku.

Dapat diambil sebagai contoh, pencipta lagu Bengawan Solo, Gesang, telah menerima royalti sebesar Rp.10.000.000,- dari seorang pengusaha pipa air minum PVC, karena pengusaha tersebut dalam mengiklankan pipa air minumnya menggunakan kalimat "air mengalir sampai jauh dari lagu Bengawan Solo miliknya. ${ }^{7}$ Itulah salah satu contoh terbaik dalam perlindungan dan penghormatan terhadap hak cipta yang diterapkan oleh pengusaha kepada karya cipta lagu seseorang. Hal ini mungkin dikarenaka pengusaha itu sadar, bahwa Gesang sébagai pencipta memiliki hak eksklusif, yang jika ada pihak lain ingin memanfaatkan karya ciptanya, ia harus diberi kompensasi. karena untuk melahrikan suatu karya cipta di bidang ilmu pengetahuan, seni dan sastera perlu pengorbanan tenaga, waktu, pikiran serta biaya yang tidak sedikit jumlahnya.

Ada negara-negara yang memasukan hak ekonomi pencipta (economic rights of the author) ke dalam Undang-Undang Hak Ciptanya secara ekspresis verbis. Misalnya, Brazil, dalam undang-undang hak ciptanya menyebutkan bahwa hak ekonomi pencipta timbul dari pemanfaatan ekonomi atas sebuah karya cipta, yang berakhir untuk kurun waktu sepanjang hidup sang pencipta. Anak-anaknya, orang tuanya atau isteri/suaminya selamanya akan menikmati hak-hak ekonomi dari pencipta yang dialihkan melalui pewarisan. Penerus (Successor) lainnya dari pencipta juga akan menikmati hak ekonomi pencipta untuk jangka waktu 60 tahun lamanya, yang dimulai dari tanggal satu Januari dari tahun berikut kematian pencipta. Karya-karya yang diterbitkan setelah kematian sang pençipta mempunyai jangka waktu yang sama yaing terhitung di mulainya perlindungan secara sah. ${ }^{8}$

Di samping Brazil, Italia juga memasukan hak ekonomi secara eksplisit ke dalam Undang-Undang Hak Ciptanya. Disebutkan

${ }^{7}$ Rooseno Harjowidagdo, Masalah Pungutan Royalti dan Perlindungan Karya Cipta (BPHN, Departemen Kehakiman RI, 1993/1994), hlm. 40.

${ }^{8}$ Paul Supnik dan Sarah Faulder, Enforcement of Copyright and Related Rights Affects The Music Industry (Netheriands: MAKLU Publishers, 1993), him. 45. 
bahwa hak ekonomi terdiri dari hak-hak pencipta untuk mengeksploitasi karya-karyanya secara ekonomis. Hak ini adalah eksklușif sifatnya, dan pada dasarnya dapat dibagi. ke dalam dua unsur yang berbeda, yaitu, hak reproduksi, hak pelaksanaan dan pertunjukan secara umum. Berlawanan dengan hak moral, yang tidak tunduk pada batasnya waktu, maka hak ekonomi beakhir 50 tahun setelah kematian pencipta. Setelah.jangka waktu itu, karya tersebut menjadi milik publik (public domain) yang dapat dipergunakan oleh siapapun, dengan ketentuan, bahwa pengguna membayar foe dalam jumlah yang kecil kepada negara, yang disebut diritto demaniale, yang berkaitan dengan pendeknya atau terpisahnya sebuah komposisi yang ditentukan oleh SIAE (Societa' Italiana degli Autoried Editori); organisasi pengumpul royalfi Italia. ${ }^{9}$

\section{Hak Moral Pencipta}

"Hak moral" sebagai hak-hak yang diakui oleh Berne Convention. Hal ini dijamin secara universal oleh para anggota Union. ${ }^{10} \mathrm{Hak}$ moral memberikan berbagai kontrol kepada pencipta terhadap penggunaan karya-karya ciptanya dengan memberikan hak kepada seorang pencipta untuk mengklaim hasil karyanya sebagai pencipta dari sebuah karya (asas "attribution" atau asas "paternity")" dan mencegah penggunaannya dengan cara yang oleh pencipta layak ditolak atau yang tidak disepakati (asas "integrity"). ${ }^{12}$ Copyright Act Amerika Serikat ${ }^{13}$ memberikan hak-hak ${ }^{14}$ kepada pemegang hak cipta, ${ }^{15}$ terlepas dari apakah pemegang hak itu adalah pencipta dari suatu karya atau kuasa dari seorang pencipta. Karena keberadaan hak moral secaraindependen berdiri di luar "hak ekonomi". ${ }^{16}$ Maka Pencipta pada tingkatan tertentu memiliki kontrol terhadap hak. tersebut walaupun karya cipta itu dieksploitasi secara kömersial dengan cara mengalihkan kepentingan-kepentingan ekonominya ke dalam karya tersebut Misalnya, komposer sebuah lagu dapat meminta hak moralnya untuk menjamin agar ia disebut sebagai pencipta, atau bahkan untuk mencegah pementasan atau pertunjukan

9 Julian Turton dan Cees van Rij, Neighbouring Rights: Artists, Producers, and their Collecting Societies, (Netherlands: MAKLU Publishers, 1990), him. 98.

${ }^{10} \mathrm{Hbid}$ art. 5(1), S. Treaty Doc. No.27 hal. 40 ("para pencipta menikmati . . . dalam negara-negara Uni selain negara asal, hak-hak yang masing-masing undang-undangnya. . . memberikan kepada warga negara mereka ... ). Untuk analisis dari dampak isu ini dalam konteks Supremacy Clause, baca kasus AEG Acquisition Corp. (Official Unsecured Creditors Comm. v. Zenith Prods.), 127 B.R. 34, 41-42 (Bankr. C.D. Cal. 1991).

"Istilah' "attribution" adalah sinonim dari gender-neutral untuk kata tradisional "patemity". "Attribution" dipergunakan Kongres Amerika dalam undang-undang hak cipta, 17 U.S.C. § 106A, dan para sarjana kontemporer, 2 MELVLLE B. NIMMER \& DAVID NIMMER, NIMMER ON COPYRIGHT, 8-255 n.6.

${ }^{12}$ Konsep ini secara rinci dijelaskan dalam part l.A.

${ }^{13}$ The Copyright Act of 1976, 17 U.S.C. $\$ \S 101-810$ (1988). , ...

14 17 U.S:C. § 106.

${ }^{15} \mathrm{lbid} 101$ menyatakan bahwa "pemegang hak cipta', sehubungan dengan salah satu hak eksklusif yang terdiri dari di dalam hak cipta yang merujuk kepada pemilik dari hak tertentu”. Jadi pencipta dari sebuah karya yang dilindungi tidak pertu menjadi pemeçang hak cipta.

${ }^{16}$ Beme, baca 1, art. 6bis(1), S. Treaty Doc. No.27 hal. 41. Baca selanjutnya part II.A. 
lagunya dalam bentuk yang ia rasa atau pahami sebagai "penyimpangan, perusakan ataumodifikasi lainnya ${ }^{17}$ yang dapat merugikan "kehormatan atau reputasinya", ${ }^{18}$ Dengan datangnya era video musik, ${ }_{1}^{19}$ teknik digital sampling ${ }^{20}$ Untuk diskusi komprehensip tentang digital sampling dan dampak perkembangan hukumnya, baca J. McGiveriin, Note,

Digital Sound Sampling Copyright and Publicity: Protecting Against the Electronic Appropriation of Sound, 87 Colum. L. Rev. 1723 (1987). Pada dasarnya digital sampling adalah sebuah metode di mana para teknisi audio sanggup mengambil/menyadap suara dari sebuah rekaman, untuk mengatur tempo atau titi nada, tapi mempertahankan karakter orijinalitasnya, dan menggabungkan suara rekaman yang diberi sampling ("sampled sound") ke dalam rekaman yang sama sekali baru. Sebenarnya sebuah lisensi untuk hak cipta dalam rekaman orijinal secara teoritis harus dimintakan sebelum sample itu dipergunakan, implementasinya menjadi masalah dan seringkali komposer mengalihkan hak ciptanya kepada pihak lain, sehingga tidak ada kontrol terhadap pemakaian hak cipta selanjutnya.

Analisa digital sampling dari karya musik cenderung memfokuskan lebih banyak lagi untuk kepentingan pelaku (performer) yang suara rekaman dicocokkan, hal ini karena pelaku (performer) lebih dekat diidentifikasi dengan rekaman musik daripada penciptanya. Baca, misalnya, Juan Carlos Thom, Comment, Digital Sampling: Old Fashioned Piracy Dressed Up in Sleek New Technology, 8 Loy. Ent. L.J. 297 (1988); Thomas C. Moglovkin, Note, Original Digital: No More Free Samples, 64 S. Cal. L. Rev. 135 (1990). Meskipun, attribution komposer (pengakuan untuk kontribusi lagu orijinalnya dalam rekaman berikutnya) dan integrity (mengontrol karakter dari penggunaan karya ciptanya) yang merupakan isu sentral dalam musik sampling, karena suara rekaman yang ber-sampling (sampled sound) pertama-tama diciptakan oleh komposer dan selanjutnya diinterpretasikan oleh pelaku (performer) dan meningkatnya popularitas musik yang menggabungkan suara rekaman yang ber-sampling, ${ }_{1}^{21}$ pengakuan hak moral di Amerika Serikat yang memberi kuasa

${ }^{17}$ Berne, baca 1, art. 6bis(1), S. Treaty Doc. No.27 hal. 41.

19 $\mathrm{bid}$.

${ }^{19}$ Baca selanjutnya part III. Digital Sampling adalah suatu proses secara digital mengisolasikan dan merekam sebuah rekaman atau rekaman dari materiyang direkam sebelumnya untuk tujuan menggabungkan rekaman yang diberi sample atau passage dengan rekaman lainnya.

${ }^{21}$ Musik rap, yang secara umum diakui mempunyai asal usul dari perkotaan Amerika kulit hitam pada pertengahan 1970an, telah mencapai popularitas luas dan sukses komersial. Baca, misalnya, Don Snowden, "Sampling: A Creative Tool or License to Steal?," LA. Times, 6 Agustus 1989, hlm. 61. Gaya musik ini sering secara mencolok menjadi ciri-ciri dari suara rekaman yang diberi sampling(sampled sound) sebagai latar belakang vokalis rap. Gaya musik lainnya juga memanfaatkan tehnologi digital mencapai hasil-hasil yang dharapkan. Dalam musik mythm-and-blues, umpamanya, dalam hitnya Natalie Cole's 1991 dalam lagu 'Unforgettable" yang memanfaatkan sampling untuk produksi duetnostalgia antara Cole dan ayahnya, Nat "King" Cole, yang meninggal $1 / 4$ abad yang lalu. Komposer Ining Gordon tidak cenderung/mudah terhadap keluhan: versi "Unforgettable 1991" telah dipilih sebagai "Song of the Year" oleh the National Academy of Recording Arts and Sciences, memberikan keuntungan kepada dalam Gordon sebuah Grammy Award 40 tahun kemudian setelah menulis laguitu pada 1951, Chris Mundy, Random Notes, Rolling Stone, 16 April 1992, hlm. 11. 
kepada para komposer untuk menuntut berbagai kontrol atas penggunaan pasca relis karya-karya mereka oleh publishers musik atau para artis musik.lainnya.

Untuk memberikan penjelasan hak moral, dapat dikemukakan bahwa hak moral (moral rights) suatu ciptaan lagu atau musik merupakan manifestasi dari pengakuan terhadap hasil karya orang lain yang sifatnya non-ekonomi. ${ }^{22}$ Hak ini diberikan untuk menjaga nama baik atau reputasi pencipta sebagai wujud lain terhadap pengakuan hasil karya intelektualnya. Penghargaan terhadap hak moral tidak dapat dinilai dari sudut materi/uang, tetapi penghargaan itu berwujud dari pemberian kekuasaan atau wewenang tertentu kepada pencipta yang bersangkutan untuk bertindak apabila ada orang lain melanggar haknya. Konsep hak moral berasal dari sistem hukum Eropa Kontinental, di mana negara-negara Eropa Kontinental seperti Perancis dan Jerman memfokuskan secara eksklusif terhadap ciptaan individual, sementara negara-negara common law, seperti Amerika Serikat dan Inggris memfokuskan kepada kepemilikan hak cipta, apakah itu pencipta, penerbit musik, penyiar atau prodeuser. ${ }^{23}$

Pada tanggal 31 Oktober 1988, Presiden Reagen menandatangani the Berne Convention Implementation Act of $1988{ }_{1}^{24}\left({ }^{\circ} \mathrm{BCIA}\right.$ atau "Implementation Act") yang mulai berlaku setelah kongres meratifikasinya pada tanggal 31. Maret 1989. Selain merangkum ketentuanketentuan hak moral dari Berne Convention, undang-undang telah mengambil upaya untuk menentang perluasan hak moral di Amerika Serikat. ${ }^{25}$ BCIA mencapai tujuan ini dengan menentukan bahwa hal itu harus ditafsirkan secara ketat Umpamanya, BCIA secara khusus

22 Eddy Damian, op.cit., hlm. 6.

23. Laura A. Pitta, Economic and Moral Rights under U.S. Copyright Law - Protection Authors and Producers in the Motion Picture Industry (Entertainment and Sports Lawyer, Winter 1995), Volume 12, Number 1, him. 3.

${ }^{24}$ Pub. L. No.100-568, 102 Stat. 2853-54 (1988): Sewaktu menandatangani BCIA pada upacara di Beverly Hills, Presiden Reagen mengatakan: "Hari ini kita merayakan sebuah kemenangan atas nama hak yang setua Union itu sendiri dan sebagai pusat dari Union kila seperti kebanyakan orang Amerika ingin melindungi hak miliknya (Property) ${ }^{\circ}$. Komentar Presiden Reagen secara tidak langsung menyatakan, bahwa hak cipta itu diakuj sebagai hak manusia. Pasal 27 ayat (2) dari The Universal Declaration of Human Rights, menyatakan bahwa ${ }^{E}$ Everyone has the right to the protection of the moral and material interests resulting from any scientific, literary or artistics production of which he is the author", dikutip dari, Patrick G. Zabatta, Ibid., hal. 1098. Bacajuga, Jane C. Ginsburg \& John M. Kemochan, One Hundred and Two Years Later: The U.S. Joins the Beme Convention, Mata Kuliah Intemational Copyright yang penulis ikuti di Franklin Pierce Law Center, Concord, New Hampshire, USA, Semester 2, 1995.

${ }^{25}$ Walaupun rancangan undang-undang asli yang diajukan untuk bergabung dengan Beme Convention mencakup hak moral, Kongres menyerahkan kepada industri media yang menentang Beme Convention karena menolak pengakuan "hak moral". "Realitas politik bahwa undang-undang dengan ketentuan hak moral tidak cisetujuj ". 134 Cong. Rec. 3083 (1988) (pernyataan anggota dowan Kestenmeir, Ketua Dewan Subkomite Paten, Hak Cipta dan Merek). 
menentukan bahwa perjanjian itu secara otomatis berlaku (self-executing), ${ }^{26}$ menurut Berne, klaim tidak dapat diajukan secara langsung. ${ }^{27}$.Akibatnya, hanya dengan dasar yang baru yang merupakan sebab yang valid atas tindakan yang dapat diprediksikan yaitu, melalui Implementation Act itu sendiri, demikian juga tambahan undang-undang yang diberlakukan untuk tunduk kepada Konvensi Berne, Di samping itu, BCIA secara tegas menyatakan tidak ada perluasan hak moral yang merupakan tujuan keikutsertaan (accession) Amerika Serikatkepadakonvensi, ${ }^{23}$ dan oleh karenanya, tidak satupun yang harus dirujuk oleh para pencipta yang mencari keringanan atas pelanggaran yang dipahami sebagai hak-hak moral mereka. ${ }^{29}$

Ketika Amerika Serikat bergabung dengan Berne Convention, Kongres mempertimbangkan apakah Undang-Undang Hak Cipta ${ }^{30}$ mensyaratkan modifikasi agar dapat mengikuti mandat Berne Convention tentang hak moral. ${ }^{31}$ Kongres menyimpulkan bahwa Berne Convention betul-betul telah memberikan jaminan kepada hak moral, ${ }^{32}$ tiadanya undangundang federal terhadap "hak moral"per $\mathrm{se}^{33}$ dan penentangan terhadap klaim yang didasarkan kepada "doktrin hak moral" oleh

${ }^{28}$ Baca H.R. Rep. No.609, Baca selanjutnya 2, hal. 28-32, yang mendiskusikan secara umum perjanjian yang segera berlaku dan tidak perlu ada penetapan lagi (self-executing) yang dikutsertakan oleh Amerika Serikat dan alasan Kongres untuk menetapkan kesimpulannya bahwa penggabungan ke Berne bukan merupakan selfexecuting.

${ }^{27} \mathrm{BCIA}$ 3(a), 102 Stat. him. 2853.

${ }^{28} \mathrm{lbid}(3)$ (b) "Certain Rights Affected", menyatakan: Ketentuan-ketentuan dari Beme Convention, dan keikutsertaan Amerika Serikat ke dalam Konvensi Beme, dan pemenuhan kewajijban-kewajiban Amerika Serikat, tidak memperluas atau mengurangi hak dari seorang pencipta atas karyanya, apakah yang diklaim itu menurut Federal, Negara Bagian (State) atau common law. (1) untukmengklaim hak cipta sebuah karya; atau (2) untuk menolak setiap penyimpangan, perusakan, atau modifikasi lainnya dari, atau tindakan yang merugikan lainnya dalam kaitannya dengan karya cipta tersebut, yang dapat merusak kehormatan atau reputasi pencipta. Ibid. Bahasa dalam section BCIA ini mencerminkan Pasal 6bis dari Beme, baca lagi 9 , section, ini nampaknya didesain untuk mencabut keseimpulan bahwa dengan kejkutsertaan ke Beme, maka Amerika Serikat telah memperluas pengakuannya terhadap hak paternity dan hak integrity.

${ }^{29}$ Para penentang hak moral berargumentasi bahwa walaupun dengan "disclaimer", keikutsertaan ke dalam Beme Convention dapat membuka pintu kepada hak moral Amerika Serikat, sebagaimana pengakuan prinsip-prinsip attribution dan integrity yang diwnjudkan dalam Beme menjad kondusif terhadap perluasan hak moral dalam undang-undang dan common law. H.R. Rep. No.609, baca2, him. 24-35. .

3017 U.S.C. $101-108$.

31 Baca 134 Cong. Rec. 3083-85 (1988) (pernyataan anggota dewan Kastenmeier).

32 "Tidak dapat diragukan lagi bahwa Beme Convention mensyaratkan anggota peserta konvensi untuk mengakomodasi karya-karyayang dilindungi di bawah Berne Convention yang hak-haknya disebutkan dalam Pasal 6bis". H.R. Rep. No.609, bacalagi 2, hlm. 32-33.

${ }_{33} 17$ U.S.C. § 115(a) (2) menentukan bahwa sebagai suatu persyaratan untuk memperoleh lisensi wajib (compulsory license), penerima lisensi tidak mengubah "dasar melodi atau karakter dari sebuah karya cipta". Dan secara lengkap mengakui hak integrity pencipta. Baca selanjutnya part II.C. 
pengadilan negara bagian ${ }^{34}$ dan pengadilan federal, Amerika Serikat sesungguhnya telah mengikuti Berne ${ }^{35}$ Kongres menguraikan bahwa secara keseluruhan bersama-sama dengan undang-undang negara bagian ${ }^{36}$ dan federa ${ }^{37}$ dan prinsip-prinsip common law negara bagian ${ }^{38}$ yang meliputi hak untuk mengklaim hak cipta dan menolak penyimpangan, walaupun prinsip-prinsip ini tidak secara teknis disebut "hak moral". ${ }^{39}$

Konsekwensinya, badan pembuat undangundang menemukan bahwa tidak perlu ada perubahan pada Undang-Undang Hak Cipta, atau meskipun yang diinginkan adaiah agar Amerika mengikuti atau tunduk kepada Berne Convention. ${ }^{40}$
Hak Cipta Amerika Serikat sejak awal menganggap hak cipta sebagai semacam hak ekonomi (seperti kursi, meja di dalam rumah), yang membenarkan pencipta dengan sesuka hat mengalihkan dan mengatur karya ciptanya. Saat ini selain sebelas negara-negara bagian seperti, New York, Massachusettes dan California dalam Undang-Undang Hak Ciptanya secara expresis verbis memberi perlindungan hak moral kepada pencipta karya cipta "Visual Art". Pada tahun 1990, Kongres Amerika Serikat meratifikasi "Visual Artist's Rights Act $1990^{\circ}$, yang memberikan perlindungan hak moral kepada beberapa karya cipta visual art. Namun, undang-undang hak cipta federal Amerika masih belum mempunyai konsep hak

${ }^{34}$ Misalnya, Shostakovich v. Twentieth Century Fox Film Corp., 196 Misc. 67, 80 N.Y.S.2d 575 (N.Y. Sup. Ct. 1948); Crimi v. Rutgers Presbyterian Church, 194 Misc. 570, 89 N.Y.S.2d813 (N.Y. Sup. Ct. 1949). Baca secara umum 2 Nimmer, baca lagi 11, hlm. 8-263 sampai 264; John H. Merryman, The Refrigerator of Bernard Buffet, 27 Hustings L.J. 1023 (1976).

${ }^{35}$ The Berne Convention Implemention Act of 1988, S. Rep. No.352, 100th Cong., $2 d$ Sess., 9-10 (1988).

${ }^{36}$ Baca selanjutnya part ll.E.

${ }^{7}$ H.R. Rep. No.609, baca lagi 2, hlm. 34. Kongres secara khusus menunjuk 17 U.S.C. 106(2), yang berkenaan dengan hak untuk membuat "karya derivatï", 17 U.S.C. 115(a) (2), yang melarang penyimpangan sebuah karya cipta musik, hak mana adalah untuk pementasan yarig dijamin oleh lisensi wajib (compulsory license), 17 U.S.C. 203, yang berkaitan dengan pengalihan dan lisensi, serta undang-undang merek (Lanham) tahun 1946 43(a), 15U.S.C. 1051 - 1127 (1988); yang merujuk kepada penunjukan yang salah tentang asalmuasal dan penggambaran yang salah (false designation of origin and false descriptions).

${ }^{39}$ Kongres menyebutkan "publisitas, pelanggaran, kontrak, kecurangan dan penyajian yang keliru, persaingan curang, pencemaran nama baik, dan pelanggaran kebebasan pribadi". H.R. Rep. No.609, baca lagi 2, hlm. 32-34.

${ }^{3} \mathrm{lbid}$ : Hukum yang digabungkan dari berbagai unsur (montage of law) adalah analog dengan hak moral yang didiskusikan, selanjutnya baca part II.E.2.

${ }^{40} \mathrm{lbid}$., hlm. 10, menetapkan pada bagian yang terkait: Komite percaya bahwa keikutsertaan Amerika ke Beme Convention seharusnya tidak mengubah undang-undang sekarang (hak moral). Oleh karenanya, $S$. 1301 tidak akan, tidak seharusnya, mengubah keseimbangan yang ada sekarang tentang hak-hak antara para pencipta Amerika dan para pengusaha, dan mengubah peraturan hak cipta dan hubuungannya dengan yang sekarang, atau mengubah efek dari kejadian sebelumnya atas putusan-putusan terdahulu. Komite juga tidak bermaksud untuk mengubah, mengurangi atau memperluas undang-undang Amerika Serikat yang sekarang yang berkaitan dengan karya hak cipta atau haknya untuk menolak penyimpangan. 
moral, sehingga tidak mungkin dapat membandingkannya dengan Undang-Undang Hak Cipta Inter Kontinental Eropa. ${ }^{41}$

Menurut Konvensi Berne revisi Roma 1929, yang mengatur hak moral pada Pasal 6bis adalah sebagai berikut:

(1) Independently of the author's economic rights, and even after the transfer of the said rights, the author shall have the right to claim authorship of the work and to object to any distortion, mutilation or other modification of, or other derogatory action in relation to, the said work, which would be prejudicial to his honor or reputation.

(2) The rights granted to the author in accordance with the preceding paragraph shall, after his death, be maintained, at least until the expiry of the economic rights, and shall be exercisable by the persons or institutions authorized by the legislation of the country where protection is claimed. However, those countries whose legisla- tion, at the moment of their ratification of or accession to this Act, does not provide for the protection after the death of the author of all the rights set out in the preceding paragraph may provide that some of these rights may, after his death, cease to be maintained.

(3) The means of redress for safeguarding the rights granted by this Article shall be governed by the legislation of the country where protection is claimed, ${ }^{42}$

Ketentuan-ketentuan Konvensi Berne di atas terus disempurnakan di Brussel dengan menambahkan keharusan adanya syarat orisinalitas pada sebuah ciptaan, kemudian pada revilsi Stockholm tolah ditambahkan ketentuan mengenai jangka waktu hak moral tersebut. Pada Pasal 6bis ayat (2) Konvensi Berne menetapkan bahwa masa perlindungan hak moral sama dengan masa perlindungan hak cipta. Selanjutnya, Pasal 27 (2) Declaration of Human Rights juga mengatur hak moral. ${ }^{43}$

${ }^{4}$ Yueh Mao Lin, 360 Legal Interest Series, Personnel Recruitment U.S., Copyright, (Taipei, Taiwan: Yung Ran Publishing Co., 1999), hlm. 187. Bdgk., Entertainment and Sport Lawyer, volume 14, November 4, 1997. Bergabungnya Amerika Serikat ke dalam Beme Convention, mau tidakmau membuat Amerika berkompromi memasukan konsep hak moral, maka pada 1990 melalui Visual Artists Right Act (NARA) secara expresis verbis dinyatakan bahwa karya cipta visualisasi memiliki hak paternity dan hak distribusi.

${ }^{42}$ Beme Convention for the Protection of Literany and Artistic Works, (World Intellectual Property Organization, Geneva, 1995), hlm. 13.

${ }^{43}$ "Human Rights, A Compilation of Intemational Instruments", (United Nations Publication, 1988), him. 6. Bdgk., WIPO, Berne Convention for the Protection of Literary and Artistic Works (Paris Act, 1971), Geneva, 1995, hlm. 22. Pasal 14ter ayat (1) Beme Convention:

"The author, or after his death the persons or institutions authorized by national legislation, shall, with respect to original works of art and original manuscripts of writers and composers, enjoy the inalienable right to an interest in any sale of the work subsequent to the first transfer by the author of the work"

Suatu tinjauan tentang perkembangan masalah di atas akan lebih memperjelas tentang pengertian hak eksklusif ini. Pada mulanya di Amerika, terdapat suatu pembatasan hak cipta dengan doktin yang disebut "first sale". Doktrin ini secara populer diartikan bahwa bilamana pemilik suatu hak cipta menjual ciptaannya (misal suatu video kaset dan phonerecord), maka orang yangmembeli barang-barang tersebut dapat menjual kembali atau menyewakannya pada pihak lain. Terhadap doktrin ini kemudian telah terjadi perubahan, yang disebabkan 
Menurut Azas "droit de suite", hak cipta tidak boleh disita oleh siapapun juga. Hak cipta merupakan hak yang bersifat pribadi yang sudah menyatu dengan penciptanya. Dengan kata lain, pencipta yang melanggar hak cipta berarti juga melanggar nilai moral manusia yang menyempurnakan hakekat manusia secara utuh.

Hak moral adalah hak-hak yang melindungi kepentingan pribadi si pencipta. Walau demikian, hak cipta dapat dipindahkan kepada pihak lain, tetapi hak moralnya tetap tidak terpisahkan dari penciptanya.

Hal di atas sejalan dengan ketentuan Pasal 14ter:2. Berne Convention yang menyebutkan bahwa:44

"It is an attempt to look after the interests of artists and other makers of artistic works. The painter or sculptor after sells his work cheaply in order to make ends meet. The work may pass through a number of hands and, in doing so, may considerably in-' crease in value. It becomes a source of revenue for those engaged in sales (dealers, experts, art critics, etc) and is often bought as good investment. This provision therefore allows the artists to follow the fortunes of his work and to profit from the increase in its value each time it changes hands Know as the droit de suite ..."

Ketentuan droit de suite bersifat hak kebendaan, karena hak cipta yang merupakan bagian dari dari Hak Kekyaan Intelektual; sehingga bersifat hak kebendaan, yang bercirikan antara lain droit de suite, yaitu hak untuk mengikuti bendanya di manapun benda itu berada atau dalam tangan siapapun benda itu berada. Jika dihubungkan dengan hak ekonomi pencipta, maka pencipta masih tetap dapat menikmati manfaat ekonomi dari hasil eksploitasi ciptaannya, sekalipun ciptaan itu telah dialihkan kepada pihak lain bahkan sampai karya cipta tersebut telah berulangkali berpindah tangan, atau telah dijual berulangkali kepada pihak lain.

Pengaturan hak moral mulai dikemukakan di dalam Konvensi Berne pada tahun 1886, tetapi sebaliknya, hak moral itu tidak ada tempat di Universal Copyright Convention, kecuali untuk satu ketentuan yang dibuat untuk menghormati. perlakuan terhadap karya-karya dalam terjemahan..$^{45}$

oleh adanya usaha penyewaan "réntals", yang memungkinkan merekam sendiri di rumah "home taping" dan yang kemudian menyuburkan usaha pembajakan "piracy" hak cipta. Oleh karenanya doktrin ini kemudian dalam perkembangannya harus diartikan, bahwa dengan adanya penjualan pertama "first sale", tidak menyebabkan hak eksklusif dari pencipta lenyap. Eksploitasi hak cipta menupakan hak èksklusif dari pencipta, karenanya setiap penyewaan video atau penyewaan piringan hitam harus mendapatkan iżn dari si pemilik hak cipta.

Sejalan dengan apa yang dijumpai di Amerika Serikat; dapat ditemukan pula dalam Konvensi Beme, berupa ketentuan bahwa pencipta masih mempunyai hak atas keuntungan dari penjualan karyanya setelah penjualan pertama oleh sipencipta dari karya itu yang lazim disebut dengan istilah "resale royalty right" atau disebutjuga droit de suite.

${ }^{44}$ WIPO Guide to the Berne Convention for the Protection of Literary and Artistic Works (Paris Act, 1971), Geneva, 1978, hlm. 90

${ }^{45}$ Leslie. E. Cotterell, Performance The Business and Law of Entertainment (London: Sweet \& Maxwell Limited, 1993), him. 427. 
Konsep hak moral terletak pada tiga prinsip:

1. Hak publikasi (the right of publication), hak untuk menentukan apakah suatu ciptaan diumumkan atau tidak diumumkan oleh pencipta;

2. Hak paternity (the right of paternity), hak mengklaim untuk mencantumkan nama pencipta dalam sebuah karya;

3. . Hak integrity (the right of integrity), hak dari seorang pencipta untuk menolak setiap penyimpangan atau perubahan atau cara perlakuan yang menyimpang terhadap karyanyayang dapat merusak kehormatan atau reputasinya. ${ }^{46}$

Sebagaimana diketahui, hak moral. sebagai hak yang tidak dapat disita atau tidak dapat dialitikan (inalienable), secara lebih langsung telah ditetapkan di negara-negara civil law. Demikian pula, meskipun tidak berkembang secara baik dan cepat, namun pada kenyataannya, pada kadar yang lebih rendah, hak moral melalui undang-undang masih terlihat di negara-negara common law. Seperti di Amerika Serikat, pada umumnya tetapi tidak semua hak moral terdapat di berbagai bentuk ketentuan dalam persaingan curang (unfair competition), baik melalui undang-undang yang terdapat di tingkat federal maupun di tingkat negara bagian (state).
Hak cipta atau "hak pencipta" di negara-negara civil law cenderung melindungi kepentingankepentingan moral dan sekaligus kepentingan ekonomi. Sebaliknya, di negara-negara common law seperti Inggris, Australia dan Amerika, lebih banyak menekankan hanya pada hakhak ekonomi. Hak moral telah berkembang dan muncul ke dalam undang-undang hak cipta di banyak negara. Inggeris, misalnya, sekarang memiliki ketentuan-ketentuan tentang hak moral di dalam Copyright, Design and Patent Act 1988, ${ }^{47}$ meskipun hak-hak itu dapat dilepaskan (waiver). Amerika Serikat mempunyai ketentuan-ketentuan baru untuk hak moral dalam Copyright Act tahun 1976, meskipun tidak ada kaitan dengan bidang musik. Perlindungan pada rekaman yang lama berubah-ubah secara luas. ${ }^{49}$

Undang-Undang Hak Cipta Jepang yang ditetapkan pada tähun 1970, dan mulai berlaku efektif tanggal 1 Januari 1971 . juga mengakui Hak Moral (iinkakuken), yang tertera di dalam Pasal 17 (1) sebagai "hak moral pencipta" dan lebih lanjut disebutkan pada Pasal 18,19 dan 20, antara lain:50

1. Right to Make Public

Hak pencipta untuk mengumumkan atau membuat agar karyanya diumumkan.

2. Right to Claim Authorship

Klaim pencipta atas sebuah karya cipta.

${ }^{45}$ Loc. cit.

${ }^{47}$ Hak Moral diatur dalam Pasal 1, Copyright, Design and Patent Act 1988". Dalam Richard Amold, Perfomers' Rights, 2ndEdition (London: Sweet \& Maxwell, 1997), him. 8.22.

${ }^{48}$ Hak Moral diatur dalam Pasal 106A, copyright Act tahun 1976, yang berjudul "Rights of Certain Authors to Altribution and integrity".

49 Paul Supnik dan Sarah Faulden, editors, Enforcement of Copyright and Related Rights Affecting The Music Industry - Reports presented at the meeting of the Internasional Association of Entertainment Lawyers (Cannes, MAKLU Publishers, Midem 1993), him. 15-16.

${ }^{50}$ Paul Edward Geller, International Copyright Law and Practice - "Japan" (Matthew Bender \& Company incorporated, 1999), him. 43. 
3. Right to the Integrity of One's Work

Hak pencipta untuk menolak setiap penyimpangan, perubahan atau perusakan atas karyanya.

Undang-Undang Hak Cipta Cina Tahun 1979 juga mengakui adanya hak moral pencipta. Setelah tahun 1985, setiap karya drama yang menjadi ciptaan atau adaptasi, penyusunan kembali atau adaptasi yang dituang secara silang (cross medium adaptation) yang dipentaskan secara publik oleh sekelompok profesional pada tingkat county atau di atasnya harus memberi penghargaan kepada pencipta yang bersangkutan dengan mencantumkan 'nama pencipta pada karya ciptanya. Dalam mengadaptasi karya-karya lainnya juga menikmati hak cipta, ${ }^{51}$ penyadur pertama-tama harus mendapatkan ijin dari pencipta asli dan membayar kepadanya menurut syarat-syarat dan ketentuan-ketentuan yang disepakati.52

Lain keadaannya di Indonesia, yang telah mengenal pengaturan hak cipta yang memberi perlindungan, antara lain, kepada ciptaan musik semenjak zaman Kolonial Hindia Belanda, yakni, Auteurswet 1912 Staatsblaad No.600 tahun 1912. Berdasarkan Pasal II Aturan Peralihan UUD'45, maka peraturan hukum Auteurswet 1912 tentang hak cipta tersebut berlaku terus sampai dengan diciptakannya
Undang Undang Hak Cipta yang baru. ${ }^{53}$ Sudah semenjak tahun 1886, di kalangan negaranegara di kawasan Eropa Barat telah memberlakukan Konvensi Berne 1886 untuk perlindungan karya cipta di bidang Sastra dan Seni; suatu pengaturan perlindungan dengan undang-undang hak cipta yang telah dianggap moderen untuk waktu itu.

Hak moral merupakan manifestasi dari pengakuan manusia terhadap hasil karya orang lain yang sifatnya non-ekonomis. Konsep hak moral berasal dari sistem hukum Eropa Kontinental, yaitu Perancis dan Jerman. Negaranegara maju seperti Perancis dan Jerman melakukan tindakan perlindungan yang saksama dan komprehensif terhadap pencipta. Banyak negara di dunia dewasa ini memberlakukan konvensi Berne, terutama terhadap hak. paternity, hak untuk dicantumkan nama pencipta dan hak integrity, hak untuk melarang pihak lain mengubah karya ciptanya. ${ }^{54}$

Konsep hak moral Eropa Kontinental tidak ditemukan dalam Copyright Act Amerika Serikat. Konsep yang dianut Amerika ialah apabila suatu karya telah dialihkan atau dilisensikan kepada pihak lain, maka pengalihan itu dapat diberlakukan secara mutlak tanpa perlu mencantumkan persyaratan yang tetap yang memberi hak kepada penciptanya ${ }^{55}$

${ }^{51}$ Dalam Peraturan Tahun 1985, tidak seperti ketentuan-ketentuan lain dalam Interim Rules Concerning Remuneration for Book-Writing, istilah "hak cipta" disebut lebih dari sepuluh kali.

${ }^{32}$ Dalam Peraturan 1985, hanya standar pembayaran untuk kelampok profesional yang diatur, tidak dininci bagaimana dan berapa besar imbalan yang harus dbayar oleh penyadur kepada pencipta aslinya, dikutip dari, Zheng Chengsi dan Michael D. Pendieton, Chinese Intellectual Property And Technology Transfer Law -. "Copyright in China" (London: Sweet \& Maxwell, 1987), hlm. 102.

${ }^{53}$ Eddy Damian, Hukum Hak Cipta menurut Beberapa Konvensi Intemasional, Undang-undang Hak Cipta 1997 dan Pertindungannya terhadap Buku serta Pejianjian Penerbitannya(Bandung: PT.Alumni, 1999), him. 140.

${ }_{54}^{54}$ Yueh Mao Lin, op.cit., hlm. 187.

${ }^{55}$ Dalam kasus, Gilliam v. American Broadcasting Cos., 538.F.2d 14 (2dCir. 1976) ("Undang-undang Hak 
Selanjutnya perbedaan antara hak ekonomi dan hak moral, sebagai berikut:

"Pencipta mempunyai hak-hak yang dinamakan hak moral dan hak ekonomi (hak eksploitasi). Kedua hak ini mempunyai kedudukan yang sejajar. Yang dinamakan hak moral tidak dapat dialihkan kepada pihak lain dan tetap berada pada pencipta. Hak ekonomi adalah hak untuk mengeksploitasi suatu ciptaan dapat dialihkan kepada pihak lain jika pencipta tidak akan mengeksploitasinya sendiri" ${ }^{n 6}$

Dengan latar belakang kajian yang dijelaskan di atas, para pencipta lagu melalui organisasi pengumpul royalti memungut royalti untuk mereka, sebagai imbalan dari lagu-lagu atau musik ciptaannya melalui kaset, $C D, L D$ dan media lainnya.

\section{Simpulan}

Undang-undang Hak Cipta No. 19 Tahun 2002 tidak secara expresis verbis menyebutkan pasal-pasal mengenai penyaturan hak ekonomi pencipta. Namun, secara implisit tersirat dalam Pasal 2 ayat (1) dan Pasal 3 ayat (2) mengenai fungsi dan sifat Hak Cipta. Hak eksklusif yang dimaksudkan dalam Pasal 2 ayat (1) adalah hak mengumumkan atau memperbanyak ciptaannya kepada pihak lain untuk memperoleh keuntungan secara ekonomi dari eksploitasi ciptaannya. Sebaliknya, UUHC yang berlaku selang secara tegas menyebutkan dalam Pasal 24 ayat (2) bahwa pencipta memiliki hak moral untuk dicantumkan nama dalam ciptaannya serta dapat mencegah bentuk-bentuk distorsi, mutilasi atäu bentuk perubahan lainnya, seperti perusakan, pemotongan, pemutarbalikan dan penggantian yang berkaitan dengan karya ciptanya, yang dapat berakibat merubah reputasi penciptanya.

Hak moral sebagai hak yang tidak dapat disita atau tidak dapat dialihkan atau dihilangkan (inalienable), secara lebih langsung ditetapkan di negara-negara civil law. Sebaliknya, walaupun tidak berkembang, lebih baik dan lebih cepat, namun, pada kadar yang lebih rendah, negara-negara penganut sistem common law juga mengatur Hak Moral ke dalam undang-undang hak ciptanya. Negaranegara common law lebih banyak menekankan pada hak-hak ekonomi.

Negara-negara yang menganut sistem civil law, seperti Perancis dan Jerman, yang menjadi pelopor hak moral di Eropa Kontinental memfokuskan ciptaan-ciptaan individual, sebaliknya, Amerika dan Inggris sebagai negara-negara common law terkemuka, memfokuskan kepada kepemilikan hak cipta, apakah itu pencipta, penerbit muat ataupun produser musik. Presiden Amerika

Cipta Amerika Serikat, sebagaimana yang ditulis sokarang, tidak mengakui hak moral atau memberikan dasar atau alasan tindakan untuk mempertahankan hak-hak moral, karena hukum mempertahankan hak ekonomi dan bukan hak moral"). Baca juga Vargas v. Esquire, Inc., 164 F.2d 522 (7th Cir. 1947). Baca secara umum 2 Nimmer, baca lagi 11, hlm. 8-263 sampai 264; Merryman, baca lagi 33, hlm. 1023.

${ }^{38}$ Eddy Damian, op.cit., hlm. 112. Staf Pengajar di beberapa perguruan tinggi swasta. Lulus S2 dari Franklin Pierce Law Center, USA., tahun 1995, memperoleh gelar MIP (Master of Intellectual Property), selanjutnya, melanjutkan studi di Golden Gate University, USA, tahun 1997, memperoleh gelar LLM, dalam bidang International Legal Studies, Gelar Doktor (S3) IImu Hukum diperoleh dari FH-UI. 
Hendra Tanu Atmadja. Konsep Hak Ekonomi dan ...

Serikat, Ronald Reagan, pada tanggal 31 Oktober 1988 menandatangani BCIA (The Berne Convention Impelementation Act of 1988). Penandatangan Presiden Reagan terhadap BCIA ini menandakan bahwa Amerika teiah merangkum ketentuanketentuan Hak Moral dari Konvensi Berne, meskipun $\mathrm{BClA}$ secara tegas mengatakan tidak ada perluasan hak moral, yang menjadi tujuan berpartisipasinya Amerika Serikat ke dalam Konvensi Berne.o

\section{Daftar Pustaka}

Arnold,Richard, Copyright, Design and Patent Act 1988, Perfomers' Rights, $2^{\text {nd }}$ Edition, London: Sweet \& Maxwell, 1997.

Chengsi, Zheng dan Michael D. Pendleton, Chinese Intellectual Property And Technology Transfer Law - "Copyright in China", London: Sweet \& Maxwell, 1987.

Cotterell, Leslie E., Performance The Business and Law of Entertainment, London: Sweet \& Maxwell Limited, 1993.

Damian, Eddy, Hukum Hak Cipta menurut Beberapa Konvensi Internasional, Undang-undang Hak Cipta 1997 dan Perlindungannya terhadap Buku serta Perjanjian Penerbitannya, Bandung: PT. Alumni, 1999.

, Eddy Damian, Hukum Hak Cipta menunutBeberapaKonvensi Intemasional, Undang-undang Hak Cipta 1997 dan Perlindungannya terhadap Buku serta Perjanjian Penerbitannya, Bandung: PT. Alumni, 1999.
Geiler, Paul Edward, International Copyright Law and Practice - "Japan", Matthew Bender \& Company Incorporated, 1999.

Goldstein, Paul, Copyright, Patent, Trademark and Related State Doctrine 935 3d ed.. 1992.

Harjowidagdo, Rooseno, Masalah Pungutan Royalti dan Perlindungan Karya Cipta, (BPHN, Departemen Kehakiman RI, 1993/1994.

Lin, Yueh Mao, 360 Legal Interest Series, Personnel Recruitment U.S., Copyright, Taipei, Taiwan: Yung Ran Publishing Co., 1999.

Merryman, John $\mathrm{H}_{\text {., }}$ The Refrigerator of Bernard Buffet, 27 Hustings L.J. 1023 (1976).

McGiveriin, J., Digital Sound Sampling Copyright and Publicity: Protecting Against the Electronic Appropriation of Sound, 87 Colum. L. Rev. 1723 (1987).

Moglovkin, Thomas C., Original Digital: No More Free Samples, 64 S. Cal. L. Rev. 135.

Pitta, Laura A., Economic and Moral Rights underU.S. Copyright Law - Protection Authors and Producers in the Motion Picture Industry, (Entertainment and Sports Lawyer, Winter 1995), Volume 12, Number 1 , hal. 3 .

Supnik, Paul dan Sarah Faulder, Enforcement of Copyright and Related Rights Affects The Music. Industry, (MAKLU Publishers, Netherlands, 1993), hal. 45. 
—_, dan Sarah Faulden, editors, "Enforcement of Copyright and Related Rights Affecting The Music Industry - Reports presented at the meeting of the Internasional Association of Entertainment Lawyers, Cannes, MAKLU Publishers, Midem 1993.

Turton, Julian dan Cees van Rij, Neighbouring Rights: Artists, Producers, and theirCollecting Societies, MAKLU Publishers,
Netherlands, 1990.

Undang:Úndang Nomor .... Tahun 1997.

WIPO Glossary of Terms of The Law of Copyright and Neighboring Rights, World Intellectual Property Organization, Geneva, 1980.

WIPO, Guide to the Berne Convention for the Protection of Literary and Artistic Works (Paris Act, 1971), Geneva, 1978.

EOEOE 